\title{
Release of Gentamicin and Vancomycin from Preformed Spacers in Infected Total Hip Arthroplasties: Measurement of Concentrations and Inhibitory Activity in Patients' Drainage Fluids and Serum
}

\author{
Dario Regis, ${ }^{1}$ Andrea Sandri, ${ }^{1}$ Elena Samaila, ${ }^{1}$ Anna Benini, ${ }^{2}$ \\ Manuel Bondi, ${ }^{1}$ and Bruno Magnan' \\ ${ }^{1}$ Department of Orthopaedic and Trauma Surgery, Integrated University Hospital, 37126 Verona, Italy \\ ${ }^{2}$ Department of Public Health and Community Medicine, Pharmacology Section, University of Verona, 37134 Verona, Italy
}

Correspondence should be addressed to Dario Regis; regisdario@siot.it

Received 22 June 2013; Accepted 6 August 2013

Academic Editors: S.-Y. Kim, M. S. Lee, and C. S. Mow

Copyright (C) 2013 Dario Regis et al. This is an open access article distributed under the Creative Commons Attribution License, which permits unrestricted use, distribution, and reproduction in any medium, provided the original work is properly cited.

\begin{abstract}
Gentamicin (G) and vancomycin (V) concentrations in drainage fluids obtained from patients during the first 24 hours after implantation of antibiotic-loaded polymethylmethacrylate (PMMA) spacers in two-stage revision of infected total hip arthroplasty were studied. The inhibitory activity of drainage fluids against different multiresistant clinical isolates was investigated as well. Seven hips were treated by implantation of industrial G-loaded spacers. Vancomycin was added by manually mixing with PMMA bone cement. Serum and drainage fluid samples were collected 1, 4, and 24 hours after spacer implantation. Antibiotics concentrations and drains bactericidal titer of combination were determined against multiresistant staphylococcal strains. The release of $\mathrm{G}$ and $\mathrm{V}$ from PMMA cement at the site of infection was prompt and effective. Serum levels were below the limit of detection. The local release kinetics of $\mathrm{G}$ and V from PMMA cement was similar, exerting a pronounced, combined inhibitory effect in the implant site. The inhibitory activity of drainage fluids showed substantial intersubject variability related to antibiotic concentrations and differed according to the pathogens tested. Gentamicin and vancomycin were released from temporary hip spacers at bactericidal concentrations, and their use in combination exerted strong inhibition against methicillin-resistant $S$. aureus and Coagulase Negative Staphylococci strains.
\end{abstract}

\section{Introduction}

Polymethylmethacrylate (PMMA) cements preloaded with antibiotics, mainly gentamicin $(G)$, are used in some cases for prophylaxis but especially for the surgical revision of prosthetic infections [1]. Frequent microorganisms isolated from joint fluid or periprosthetic tissue are the Coagulase Negative Staphylococci (CoNS), S. aureus and most commonly $S$. epidermidis, and Streptococcus haemolyticus [2]. Currently, the routinely used methods of culturing are likely to detect in most, not all, cases the pathogens possibly involved in infection of a total hip arthroplasty (THA) [3]. Some difficult-totreat bacteria, such as methicillin-resistant $S$. aureus (MRSA), methicillin-resistant CoNS, enterococci, and Pseudomonas aeruginosa present much greater failure risks. In a number of cases $S$. aureus infection is the significant factor associated with treatment failure, along with retained prosthesis and treatment with inappropriate antibiotics [4]. A two-stage revision of an infected arthroplasty with antibiotic-loaded spacer implantation is considered an effective procedure for these infections $[2,5]$.

Because of the increasing resistance of staphylococci to gentamicin, surgeons commonly add antibiotics to bone cement directly in the operating room according to microorganism susceptibility. Vancomycin (V) is frequently utilized because of its antimicrobial activity against MRSA and other Gram-positive cocci and anaerobes, such as propionibacteria. 
This drug delivery system offers the advantage of local release of high antibiotic concentrations, which considerably exceed those obtained after systemic administration.

Combining two antibiotics in bone cement is common in clinical practice. As the effect of mixing on elution characteristics is still debated, only limited data are available on antibiotic release in vivo from prosthetic devices after implantation $[6-8]$, as well as after removal $[9,10]$. Moreover, the wide variability of the results makes it difficult to compare studies and draw general conclusions. The properties of various bone cements, the preparation, type and concentrations of different antibiotics mixed with PMMA, the pathogens involved, and patient characteristics are all factors contributing to the clinical outcome and should be taken into account in the final evaluation of treatments. We previously observed that gentamicin and vancomycin were still present in explanted spacers after 3 to 9 months of permanence in situ; the residual drug concentrations showed great variability [11].

Open questions are related to the concentrations of antibiotics at the implantation site and to the duration of their effective inhibitory activity.

The aims of the present study were (1) to measure the concentrations of antibiotics present at the infection site in the first few hours after implanting the hip preformed spacer; (2) to evaluate if antibiotics are released in large amounts consistent with the results of in vitro experiments; (3) and finally to assess the antimicrobial activity of drainage fluids against multiresistant microorganisms.

To the best of our knowledge, this is the first study which details the antibiotic release from industrially manufactured temporary spacers in infected hip arthroplasties.

\section{Materials and Methods}

From January 2004 to September 2005, 7 patients who received preformed spacers for two-stage revision of a THA were investigated. There were 4 male and 3 female patients, whose age ranged between 51 and 78 years (average, 65.6 years) at the time of implantation. All THAs were performed for osteoarthritis. Diagnosis was suspected on the basis of clinical findings (persistent pain or recurrence 3-5 years later, presence of a secreting fistula, swelling, erythema, local warmth, and restricted range of motion) and of the ESR and the CRP (which were always elevated) [12]. Standard X-ray and scintigraphy with labeled leukocytes were performed in all the patients [12-16]. Intraoperative biopsy of bone and soft tissue was always carried out, and the Feldman and the Athanasou criteria were used to define infection $[17,18]$. The management of infection included removal of the prosthesis and insertion of a preformed antibiotic-loaded PMMA spacer (Tecres S.p.A., Sommacampagna, Verona, Italy).

The hip preformed spacer, Spacer-G, has a structure in stainless steel AISI 316ESR, and it is available in 3 different diameters of the head $(46,54$, and $60 \mathrm{~mm})$ and 2 lengths of the stem (153 and $270 \mathrm{~mm}$ ). The gentamicin concentration is $2.5 \%$. Currently, it is also available with flat rod (Flat Stem Spacer-G) and industrially supplemented with vancomycin at concentration of $2.5 \%$ (Vancogenx Hip-Space).
Removal of the septic implant was followed by a thorough periprosthetic debridement and implantation of the spacer (Figures 1(a) and 1(b)). A vancomycin-loaded bone cement was prepared manually by mixing $40 \mathrm{~g}$ of powered cement PMMA polymer (Cemex, Tecres S.p.A., Sommacampagna, Verona, Italy) and $1 \mathrm{~g}$ of vancomycin (Vancocin, Eli Lilly, Milan, Italy). Finally, $35 \mathrm{~mL}$ of liquid MMA monomer was added and carefully mixed with a spatula $[11,19]$. Vancomycin addition to hip spacers was obtained by filling with the cement mixture $17-18$ holes (10-12 $\mathrm{mm}$ diameter, $2-3 \mathrm{~mm}$ depth) which were drilled in the surface of the Spacer$\mathrm{G}$ immediately before implantation (Figure 2). Each device received $6-7 \mathrm{~g}$ of cement, corresponding to $150-170 \mathrm{mg}$ of vancomycin, respectively. Vancomycin (Vancocin, $1 \mathrm{~g}$, twice daily) was also administered intravenously to 1 patient as control case.

Two- to 3-week standard parenteral antibiotics administration (cefazolin, Cefamezin, Pfizer Italia, Roma, Italy; $1 \mathrm{~g}$ four times a day; i.v.) was given to the remaining patients, followed by oral therapy, according to infectious disease consultant, for an overall treatment of 6 weeks. Outpatients clinical evaluation was arranged monthly, including laboratory tests (WBC, ESR, and CRP) and radiographic examination (anteroposterior and lateral views). Due to an immediate pain relief after surgery, a standard physiotherapy regimen including continuous passive motion was carried out. Partial to total weight bearing on the operated leg using two crutches was allowed until reimplantation.

In all the cases, eradication of infection was obtained, and the second surgical step, including the removal of the spacer and the application of a new THA, was performed successfully when patient's laboratory indices became normal and when bone scintigraphy with labeled leukocytes was negative for infection. In the postoperative period, parenteral antibiotic treatment was administered for 6 weeks in all the patients according to the pathogen identification or with broad-spectrum antibiotics in case of lack identification (2 patients) starting from day 3rd with the exception of the patients control case which started preoperatively.

Fluids drainage and serum samples to 1, 4, and 24 hours after the first surgical step were collected in all cases. Concentrations of gentamicin and vancomycin were determined in parallel by Fluorescence Polarisation Immunoassay (TDx, Abbott). The lowest measurable level of drug concentration was defined as that which could be distinguished from 0 with 95\% confidence; this was determined as $0.27 \mathrm{mg} / \mathrm{L}$ for $\mathrm{G}$ and $2.0 \mathrm{mg} / \mathrm{L}$ for $\mathrm{V}$ [11]. The antibacterial activity determination was also done on different orthopaedic strains isolates with differing degrees of resistance. Bacterial strains were multiresistant clinical isolates obtained from Intensive Care Unit in patients, kindly provided by the Microbiology Department of the local university (Table 1).

The MICs of gentamicin, vancomycin, and their combinations were determined using the broth microdilution technique as recommended by the CLSI (Clinical and Laboratory Standards Institute) guidelines [20]. Resistance of the staphylococcus strains was determined according to international standard methods [21]. Resistance to gentamicin was defined by $\mathrm{MIC}_{90}>32 \mathrm{mg} / \mathrm{L}$; gentamicin-intermediate resistance by 


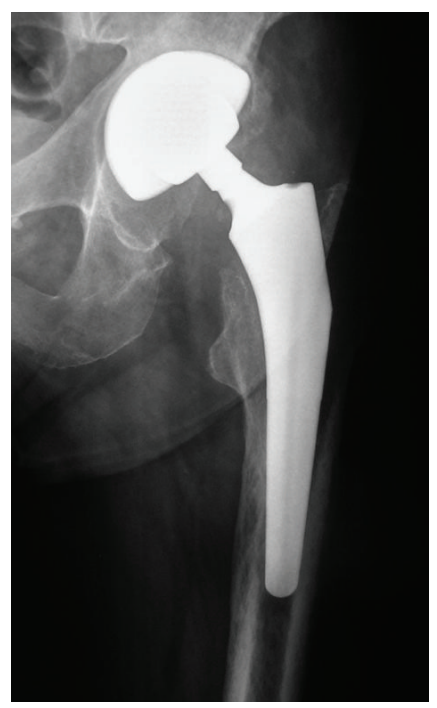

(a)

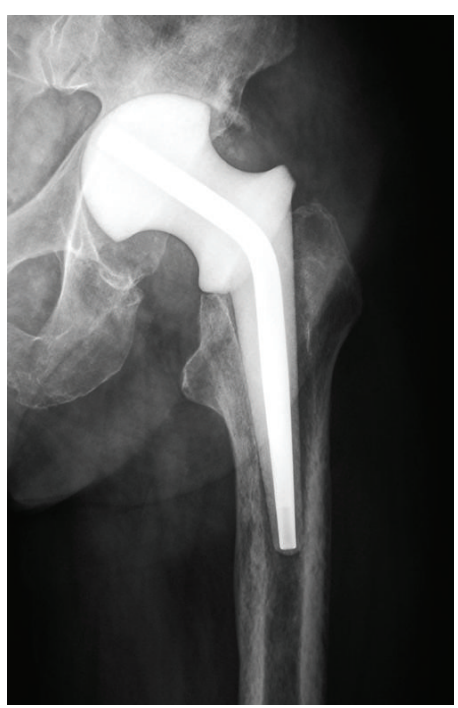

(b)

FIGURE 1: Preoperative X-ray of a total hip arthroplasty complicated by chronic infection (a). Radiograph obtained after removal of the infected prosthesis and implantation of an industrially manufactured spacer (b).

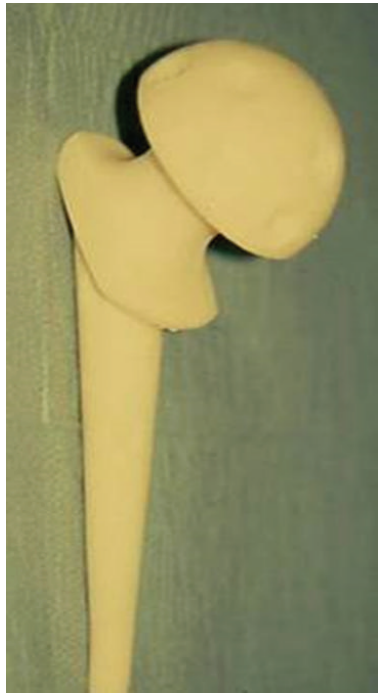

FIGURE 2: Image of the preformed gentamicin-loaded cement spacer after surgical addition of vancomycin using the "surface drill hole" technique.

$\mathrm{MIC}_{90}=8.0 \mathrm{mg} / \mathrm{L}$, and resistance to vancomycin by $\mathrm{MIC}_{90}>$ $4.0 \mathrm{mg} / \mathrm{L}$ for the strains tested. Synergy testing was performed in duplicate using the chequerboard method in microtiter plates with Mueller-Hinton Broth (MHB, Difco). Gentamicin and vancomycin were diluted in $\mathrm{MHB}$ and tested at different twofold concentrations (from 0.3 to $20.0 \mathrm{mg} / \mathrm{L}$ ) against all strains (final inoculum $1 \times 10^{5} \mathrm{CFU} / \mathrm{mL}$ ). The fractional inhibitory concentration index (FICI) was calculated and interpreted for each strain [22]: the FICI was defined as synergistic if the values were $<0.5$, indifferent or additive if the values were from 0.5 to 4.0 , and antagonistic if the values were $>4.0$ [23] (Table 1).
TABLE 1: In vitro activity of gentamicin and vancomycin in combination against multiresistant clinical isolates.

\begin{tabular}{lccc}
\hline \multicolumn{4}{c}{ Vancomycin + gentamicin } \\
Strain & \multicolumn{3}{c}{ MIC (mg/L) } \\
& Vancomycin & Gentamicin & FICI \\
\hline S. aureus & 2.5 & 10 & 0.15 \\
S. epidermidis & 2.5 & 3750 & 1.00 \\
S. haemolyticus & 1.25 & 3750 & 1.00 \\
S. haemolyticus & 1.25 & 3750 & 1.00 \\
Methicillin-resistant & & & \\
S. epidermidis & 2.5 & 58.6 & 0.50 \\
Methicillin-resistant & 1.25 & 15 & 1.02 \\
S. hominis Methicillin-resistant & 156.25 & 5.0 & 0.25 \\
E. coli & 1250 & 5.0 & 0.12 \\
P. aeruginosa & & &
\end{tabular}

Twofold serial dilutions of patient drainages were prepared in microtiter plates using Mueller-Hinton Broth as diluent. The final volume was $0.1 \mathrm{~mL}$ in each well, and $0.01 \mathrm{~mL}$ of each strain from overnight cultures was added to each well, including a growth control well, without drainage; an absolute control (MHB only) was also provided. Microplates were incubated for at least $18 \mathrm{~h}$ at $37^{\circ} \mathrm{C}$. Subcultures for the 99.9\% bactericidal endpoints were performed in Brain Heart Agar. The drainage fluid bactericidal titer (DBT) is a measure of the drainage fluid killing capacity against the infecting organism; it was determined as the highest fluid dilution achieving $99.9 \%$ bacterial killing. The score 3, corresponding to a $1 / 8$ dilution, was considered the lowest effective titer for orthopaedic infections $[24,25]$. 
TABLE 2: Bactericidal titer of drainage fluids collected from 7 patients within the first 24 hours of spacer implantation against multiresistant clinical isolates.

\begin{tabular}{|c|c|c|c|c|c|c|c|c|c|c|c|c|c|c|}
\hline \multirow{3}{*}{ Strain } & \multicolumn{14}{|c|}{ DBT } \\
\hline & \multicolumn{2}{|c|}{ PT 1} & \multicolumn{2}{|c|}{ PT 2} & \multicolumn{2}{|c|}{ PT 3} & \multicolumn{2}{|c|}{ PT 4} & \multicolumn{2}{|c|}{ PT 5} & \multicolumn{2}{|c|}{ PT 6} & \multicolumn{2}{|c|}{ PT 7} \\
\hline & $1 \mathrm{~h}$ & $24 \mathrm{~h}$ & $1 \mathrm{~h}$ & $24 \mathrm{~h}$ & $1 \mathrm{~h}$ & $24 \mathrm{~h}$ & $1 \mathrm{~h}$ & $24 \mathrm{~h}$ & $1 \mathrm{~h}$ & $24 \mathrm{~h}$ & $1 \mathrm{~h}$ & $24 \mathrm{~h}$ & $1 \mathrm{~h}$ & $24 \mathrm{~h}$ \\
\hline S. aureus & 6 & 9 & 9 & 9 & 6 & 5 & 5 & 5 & 3 & 2 & 3 & 4 & 6 & 4 \\
\hline S. epidermidis & 3.3 & 6 & 5 & 3 & 4 & 4 & 4 & 4 & 0 & 1 & 4 & 4 & 5 & 3 \\
\hline S. haemolyticus & 3.3 & 6 & 6 & 7 & 4 & 3 & 4 & 4 & 0 & 1 & 3 & 3 & 4 & 3 \\
\hline S. haemolyticus Methicillin-resistant & 3 & 5 & 4 & 3 & 4 & 4 & 4 & 3 & 0 & 0 & 4 & 5 & 4 & 3 \\
\hline S. epidermidis Methicillin-resistant & 3.3 & 6 & 4.3 & 2 & 4 & 3 & 4 & 4 & 0 & 0 & 7 & 7 & 4 & 3 \\
\hline S. hominis Methicillin-resistant & 5 & 8 & 7 & 5 & 5 & 5 & 4 & 5 & 0 & 1 & 5 & 5 & 6 & 4 \\
\hline E. coli & 6 & 9 & 5 & 6 & 4 & 4 & 4 & 5 & 2 & 1 & 5 & 3 & 6 & 4 \\
\hline P. aeruginosa & 4 & 6 & 5 & 5 & 4 & 4 & 3 & 4 & 0 & 0 & 5 & 6 & 5 & 3 \\
\hline
\end{tabular}

\section{Results}

The release of gentamicin from PMMA cement at the site of infection showed high local concentrations (range 15.0$90.0 \mathrm{mg} / \mathrm{L}$ ) in the first few hours after spacer implantation. Gentamicin serum levels were invariably very low $(<0.2-1.0 \mathrm{mg} / \mathrm{L})$. The local administration of vancomycin (2.5\%) produced high concentrations (ranging from 13.8 to $40.0 \mathrm{mg} / \mathrm{L}$ ) at the implant site in the first hour. This behaviour persisted 4 and 24 hours after spacer implantation. The corresponding serum levels were below the threshold for systemic toxicity $(<10 \mathrm{mg} / \mathrm{L}$ for gentamicin and $<40 \mathrm{mg} / \mathrm{L}$ for vancomycin); however, vancomycin attained therapeutic concentrations after parenteral administration, but again below systemic toxicity limits.

The levels of each antibiotic in drainage fluids were all above the concentrations needed to inhibit susceptible bacteria, and their use in combination appears to be capable of exerting pronounced antimicrobial activity and also a synergistic effect against some multiresistant microorganisms.

The DBT score was high (above 3 ) in the first few hours after drug release (1/8 titer) for all strains tested; an effective titer was maintained for almost 24 hours. The same drainage fluid presented different inhibitory capacities against various multiresistant strains. For example, patient n. 1 exhibited good inhibitory activity $(\mathrm{DBT}=6)$ against E. coli, S. aureus, and lower inhibitory activity $(\mathrm{DBT}=4)$ against $P$. aeruginosa; patient $\mathrm{n}$. 6 had good inhibitory activity $(\mathrm{DBT}=7)$ against $S$. epidermidis Methicillin-resistant and lower inhibitory activity (DBT $=3-4)$ against $S$. aureus, $S$. haemolyticus (2 strains), and S. epidermidis. Patient n. 7 showed good inhibitory activity $(\mathrm{DBT}=6)$ against $S$. hominis, $S$. aureus and lower inhibitory activity $(\mathrm{DBT}=4)$ against S. haemolyticus (2 strains) and S. epidermidis. Moreover, the fluid maintained high activity against the Gram-negative strains E. coli and P. aeruginosa (Table 2).

The fluid collected from patient who also received local and systemic vancomycin (control case) was inhibitory against the majority of tested strains and higher against $S$. aureus during the first 24 hours after implantation.

Depending on the different antibiotic concentrations in the microtiter plates and microorganisms tested, the samples inhibitory activity was variable. DBT scores indicated good inhibitory activity after 24 hours when $\mathrm{G}$ and $\mathrm{V}$ in combination were present at adequate concentrations (in these conditions, $\geq 8 \mathrm{mg} / \mathrm{L}$ and $\geq 2 \mathrm{mg} / \mathrm{L}$, resp.) and when the $\mathrm{G}: \mathrm{V}$ ratio was at least $2: 1$.

Pain relief after application of the spacer was obtained in all cases, and partial weight bearing with crutches was allowed. There were no general or local complications (dislocation, breakage, and loosening of the spacer). No adverse drug reaction (hypersensitivity, erythema, edema, etc.) attributable to gentamicin or vancomycin was reported after local and systemic drug administration.

\section{Discussion}

Periprosthetic hip infection following THA is a serious problem, and different treatment options related to the type of infection are available. In two-stage revision procedure, temporary spacers made of antibiotic-loaded PMMA represent a viable option for a chronically infected THA, allowing local antibiotic delivery and maintaining soft tissue length, which facilitates reimplantation $[10,26]$.

Industrially preformed spacer has some advantages such as ease of use, high availability in sizes, and excellent acetabular bone quality at the time of revision [26]. With the use of this specific device, many authors have reported good eradication rate ranging from 80 to $93.3 \%$ [26-29]. Industrial production ensures procedure standardization eliminating the time necessary to intraoperative manufacturing [26]. However, spacer-related complications, such as dislocations and fractures, have been described as well, ranging from 3.3 to $17 \%$ [26-29].

In this study, the release of gentamicin and vancomycin in the first 24 hours after implantation of hip preformed spacers was evaluated. Gentamicin and vancomycin concentrations were very high and strongly bactericidal in suction drainage fluid samples one hour after spacer implantation and remained high for at least 24 hours. These results confirm the findings of Anagnostakos et al., who firstly reported high concentrations of antibiotics in drainage fluids in the first few days after implantation of beads or spacer [10]. In addition, we 
observed different inhibitory capacities exerted by the same drainage fluid against several multiresistant clinical isolates.

Gentamicin and vancomycin concentrations determined singly in drainage fluids in the first 24 hours were very high and stable but not inhibitory against multiresistant strains. However, gentamicin and vancomycin act sinergistically against several multiresistant staphylococcal strains, as shown by the FICI and the DBT scores. The therapeutic rationale for combining $\mathrm{G}$ and $\mathrm{V}$ depends on the susceptibility of the infecting pathogens, and vancomycin use should be limited to infections likely to be caused by more resistant Gram-positive bacteria, such as S. epidermidis, methicillinresistant staphylococci, CoNS, or enterococci [30, 31]. Cefazolin, not dosed, could contribute to antimicrobial activity of drainage fluids; it is effective mainly against susceptible strains, S. aureus (9A28) and S. aureus (3A10), and ineffective against the multiresistant strains as confirmed recently [32].

In our patients, gentamicin and vancomycin serum levels were below the threshold for systemic toxicity, and no signs of nephrotoxicity or local cytotoxic effects were observed. These data confirm the safety aspects of local drug delivery and the good tolerability of systemic and local levels. A low frequency of adverse reactions has been reported with antibiotic-containing spacers [10], though damage to the kidney and increased mortality has also been reported. In a systematic review including 10 observational studies, Luu et al. [33] showed an average incidence of acute kidney injury of $4.8 \%$ using antibiotic spacer. Berend at al. [34] studied mortality rates associated with two-stage treatment of infected THA in 202 patients undergoing two-stage treatment for infection, including removal of all implants and foreign material with implantation of an antibiotic-loaded cement spacer in the first stage followed by intravenous culturespecific antibiotics for a minimum of 6 weeks. Fourteen patients $(7 \%)$ died before reimplantation, and two were not candidates because of medical comorbidities. The 90-day mortality rate after the first-stage debridement was $4 \%$.

\section{Conclusions}

The results of the present investigation provide data on the release of gentamicin and vancomycin from preformed antibiotic cement spacers in the first 24 hours after implantation, supporting the potential clinical efficacy of the gentamicin-vancomycin combination in two-stage management of infected THA. Preformed spacers loaded with G and $\mathrm{V}$ are a safe method of delivering high concentration of antibiotics to the infection site with low serum levels, achieving effective release kinetics. The use of industrially preformed spacers should be advantageous in terms of standardization of the device characteristics, uniform cement mix with antibiotics, and reproducible drug release.

\section{Conflict of Interests}

The authors declare that they have no potential conflict of interests.

\section{References}

[1] M. Diefenbeck, T. Mückley, and G. O. Hofmann, "Prophylaxis and treatment of implant-related infections by local application of antibiotics," Injury, vol. 37, supplement 2, pp. S95-S104, 2006.

[2] E. Moran, I. Byren, and B. L. Atkins, "The diagnosis and management of prosthetic joint infections," Journal of Antimicrobial Chemotherapy, vol. 65, no. 3, pp. iii45-iii54, 2010.

[3] C. A. Fux, P. Stoodley, L. Hall-Stoodley, and J. W. Costerton, "Bacterial biofilms: a diagnostic and therapeutic challenge," Expert Review of Anti-Infective Therapy, vol. 1, no. 4, pp. 667683, 2003.

[4] J. Lee, C.-I. Kang, J. H. Lee et al., "Risk factors for treatment failure in patients with prosthetic joint infections," Journal of Hospital Infection, vol. 75, no. 4, pp. 273-276, 2010.

[5] A. D. Hanssen and J. A. Rand, "Evaluation and treatment of infection at the site of a total hip or knee arthroplasty," Journal of Bone and Joint Surgery A, vol. 80, no. 6, pp. 910-922, 1998.

[6] A. González della Valle, M. Bostrom, B. Brause, C. Harney, and E. A. Salvati, "Effective bactericidal activity of tobramycin and vancomycin eluted from acrylic bone cement," Acta Orthopaedica Scandinavica, vol. 72, no. 3, pp. 237-240, 2001.

[7] J. Kelm, T. Regitz, E. Schmitt, W. Jung, and K. Anagnostakos, "In vivo and in vitro studies of antibiotic release from and bacterial growth inhibition by antibiotic-impregnated polymethylmethacrylate hip spacers," Antimicrobial Agents and Chemotherapy, vol. 50, no. 1, pp. 332-335, 2006.

[8] S. L. Henry and K. P. Galloway, "Local antibacterial therapy for the management of orthopaedic infections: pharmacokinetic considerations," Clinical Pharmacokinetics, vol. 29, no. 1, pp. 3645, 1995.

[9] J. Mutimer, G. Gillespie, A. M. Lovering, and A. J. Porteous, "Measurements of in vivo intra-articular gentamicin levels from antibiotic loaded articulating spacers in revision total knee replacement," Knee, vol. 16, no. 1, pp. 39-41, 2009.

[10] K. Anagnostakos, P. Wilmes, E. Schmitt, and J. Kelm, "Elution of gentamicin and vancomycin from polymethylmethacrylate beads and hip spacers in vivo," Acta Orthopaedica, vol. 80, no. 2, pp. 193-197, 2009.

[11] E. Bertazzoni Minelli, A. Benini, B. Magnan, and P. Bartolozzi, "Release of gentamicin and vancomycin from temporary human hip spacers in two-stage revision of infected arthroplasty," Journal of Antimicrobial Chemotherapy, vol. 53, no. 2, pp. 329-334, 2004.

[12] N. V. Greidanus, B. A. Masri, D. S. Garbuz et al., "Use of erythrocyte sedimentation rate and C-reactive protein level to diagnose infection before revision total knee arthroplasty: a prospective evaluation," Journal of Bone and Joint Surgery A, vol. 89, no. 7, pp. 1409-1416, 2007.

[13] W. J. Gillespie, "Prevention and management of infection after total joint replacement," Clinical Infectious Diseases, vol. 25, no. 1, pp. 1310-1317, 1997.

[14] K. P. Iyengar and S. Vinjamuri, "Role of $99 \mathrm{mTc}$ Sulesomab in the diagnosis of prosthetic joint infections," Nuclear Medicine Communications, vol. 26, no. 6, pp. 489-496, 2005.

[15] B. Zicat, D. M. Rahme, K. Swaraj, S. Qurashi, R. Loneragan, and H. Van der Wall, "Septic arthritis of the acromioclavicular joint: Tc-99m leukocyte imaging," Clinical Nuclear Medicine, vol. 31, no. 3, pp. 145-146, 2006.

[16] D. Fuster, A. Soriano, S. Garcia et al., "Usefulness of 99mTcciprofloxacin scintigraphy in the diagnosis of prosthetic joint 
infections," Nuclear Medicine Communications, vol. 32, no. 1, pp. 44-51, 2011.

[17] N. A. Athanasou, R. Pandey, R. de Steiger, D. Crook, and P. M. Smith, "Diagnosis of infection by frozen section during revision arthroplasty," Journal of Bone and Joint Surgery B, vol. 77, no. 1, pp. 28-33, 1995.

[18] D. S. Feldman, J. H. Lonner, P. Desai, and J. D. Zuckerman, "The role of intraoperative frozen sections in revision total joint arthroplasty," Journal of Bone and Joint Surgery A, vol. 77, no. 1, pp. 1807-1813, 1995.

[19] E. Bertazzoni Minelli, C. Caveiari, and A. Benini, "Release of antibiotics from polymethylmethacrylate cement," Journal of Chemotherapy, vol. 14, no. 5, pp. 492-500, 2002.

[20] Clinical and Laboratory Standards Institute, "Methods for dilution antimicrobial susceptibility tests for bacteria that grow aerobically," Approved Standard M7-A8, CLSI, Wayne, Pa, USA, 2009, 8th edition.

[21] Clinical and Laboratory Standards Institute, "Performance standards for antimicrobial susceptibility testing," 19th Informational Supplement M100-S19, CLSI, Wayne, Pa, USA, 2009.

[22] G. M. Eliopoulos and R. C. Moellering, "Antimicrobial combination," in Antibiotics in Laboratory Medicine, V. Lorian, Ed., pp. 330-396, Williams \& Wilkins, Baltimore, Md, USA, 4th edition, 1996.

[23] I. C. Gyssens, "Vancomycin," in Kucers' the Use of Antibiotics, M. L. Grayson, S. M. Crowe, J. S. McCarthy et al., Eds., pp. 569-600, Hodder Arnold, London, UK, 6th edition, 2010.

[24] D. Amsterdam, "Susceptibility testing of antimicrobials in liquid media," in Antibiotics in Laboratory Medicine, V. Lorian, Ed., pp. 52-111, Williams \& Wilkins, Baltimore, Md, USA, 4th edition, 1996.

[25] C. W. Stratton, "The usefulness of the serum bactericidal test in orthopedic infections," Orthopedics, vol. 7, no. 10, pp. 1579-1580, 1984.

[26] D. R. P. Neumann, T. Hofstaedter, C. List, and U. Dorn, “Twostage cementless revision of late total hip arthroplasty infection using a premanufactured spacer," Journal of Arthroplasty, vol. 27, no. 7, pp. 1397-1401, 2012.

[27] B. Magnan, D. Regis, R. Biscaglia, and P. Bartolozzi, "Preformed acrylic bone cement spacer loaded with antibiotics: use of twostage procedure in 10 patients because of infected hips after total replacement," Acta Orthopaedica Scandinavica, vol. 72, no. 6, pp. 591-594, 2001.

[28] F. D’Angelo, L. Negri, T. Binda, G. Zatti, and P. Cherubino, “The use of a preformed spacer in two-stage revision of infected hip arthroplasties," Musculoskeletal surgery, vol. 95, no. 2, pp. 115120, 2011.

[29] R. M. Degen, J. R. Davey, J. R. Davey, J. L. Howard, R. W. McCalden, and D. D. R. Naudie, "Does a prefabricated gentamicin-impregnated, load-bearing spacer control periprosthetic hip infection?" Clinical Orthopaedics and Related Research, vol. 470, no. 10, pp. 2724-2729, 2012.

[30] E. Hershberger, J. R. Aeschlimann, T. Moldovan, and M. J. Rybak, "Evaluation of bactericidal activities of LY333328, vancomycin, teicoplanin, ampicillin-sulbactam, trovafloxacin, and RP59500 alone or in combination with rifampin or gentamicin against different strains of vancomycin-intermediate Staphylococcus aureus by time-kill curve methods," Antimicrobial Agents and Chemotherapy, vol. 43, no. 3, pp. 717-721, 1999.
[31] H. van de Belt, D. Neut, W. Schenk, J. R. van Horn, H. C. van der Mei, and H. J. Busscher, "Staphylococcus aureus biofilm formation on different gentamicin-loaded polymethylmethacrylate bone cements," Biomaterials, vol. 22, no. 12, pp. 1607-1611, 2001.

[32] S. W. Ueng, P. H. Hsieh, H. N. Shih et al., "Antibacterial activity of joint fluid in cemented total-knee arthroplasty: an in vivo comparative study of polymethylmehacrylate with and without antibiotic loading," Antimicrobial Agents and Chemotherapy, vol. 56, no. 11, pp. 5541-5546, 2012.

[33] A. Luu, F. Syed, G. Raman et al., "Two-stage arthroplasty for prosthetic joint infection: a systematic review of acute kidney injury, systemic toxicity and infection control," The Journal of Arthroplasty, 2013.

[34] K. R. Berend, A. V. Lombardi Jr., M. J. Morris, A. G. Bergeson, J. B. Adams, and M. A. Sneller, "Two-stage treatment of hip periprosthetic joint infection is associated with a high rate of infection control but high mortality," Clinical Orthopaedic and Related Research, vol. 471, no. 2, pp. 510-518, 2013. 


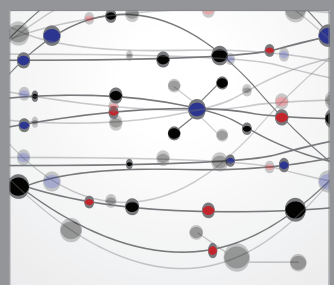

The Scientific World Journal
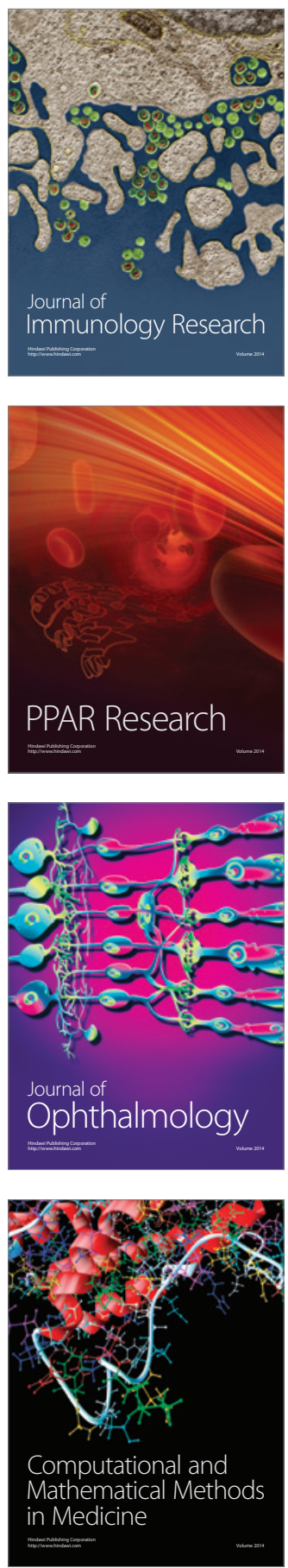

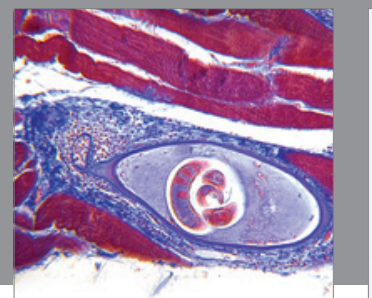

Gastroenterology

Research and Practice
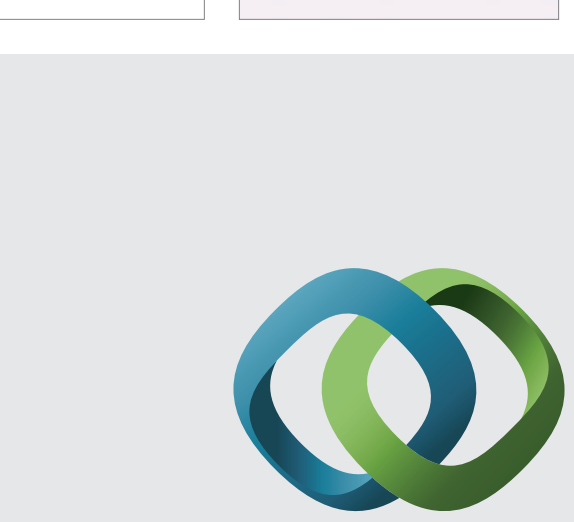

\section{Hindawi}

Submit your manuscripts at

http://www.hindawi.com
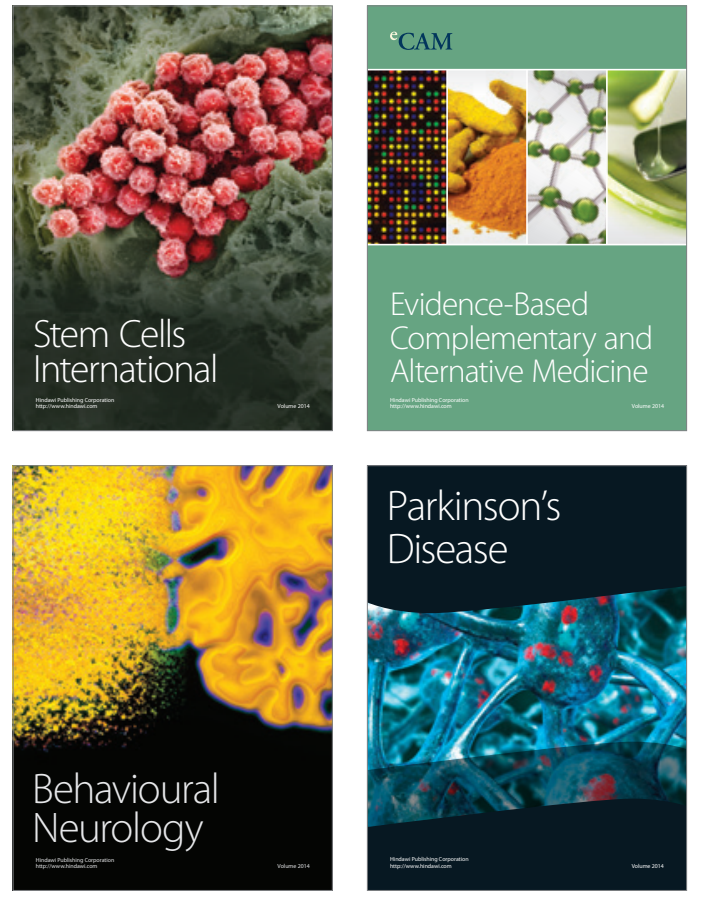
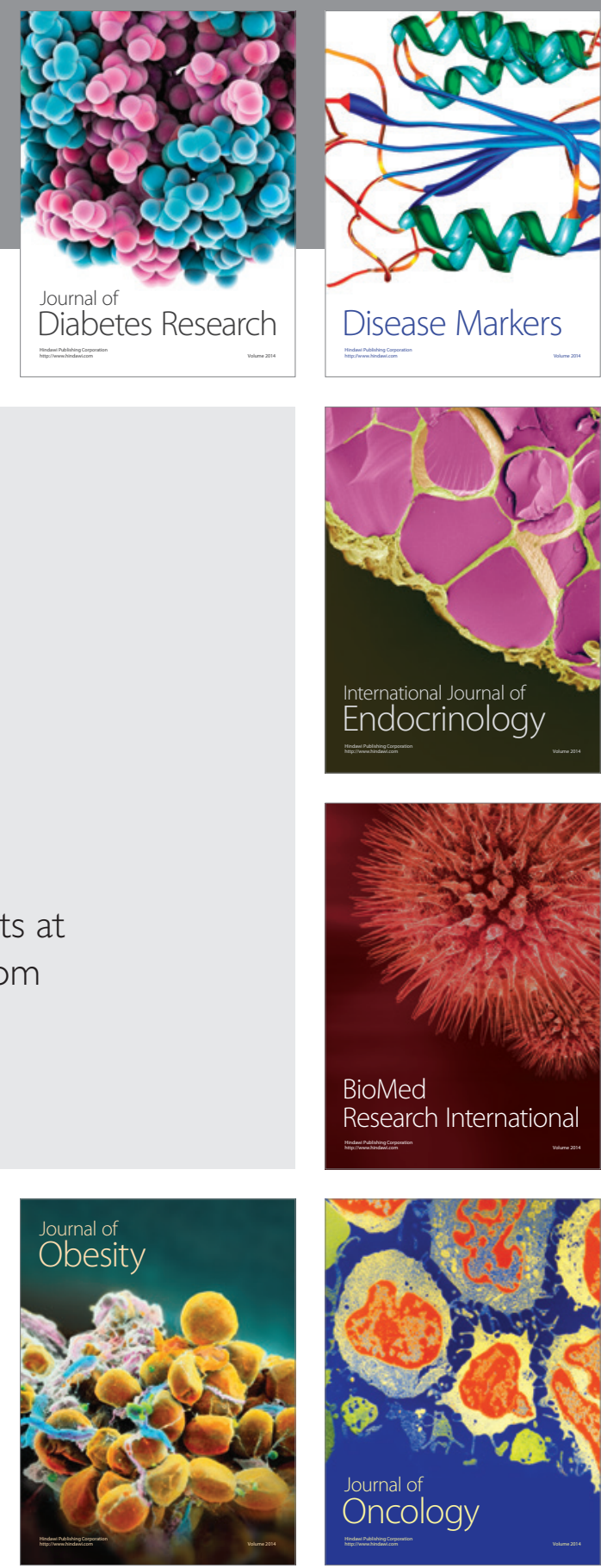

Disease Markers
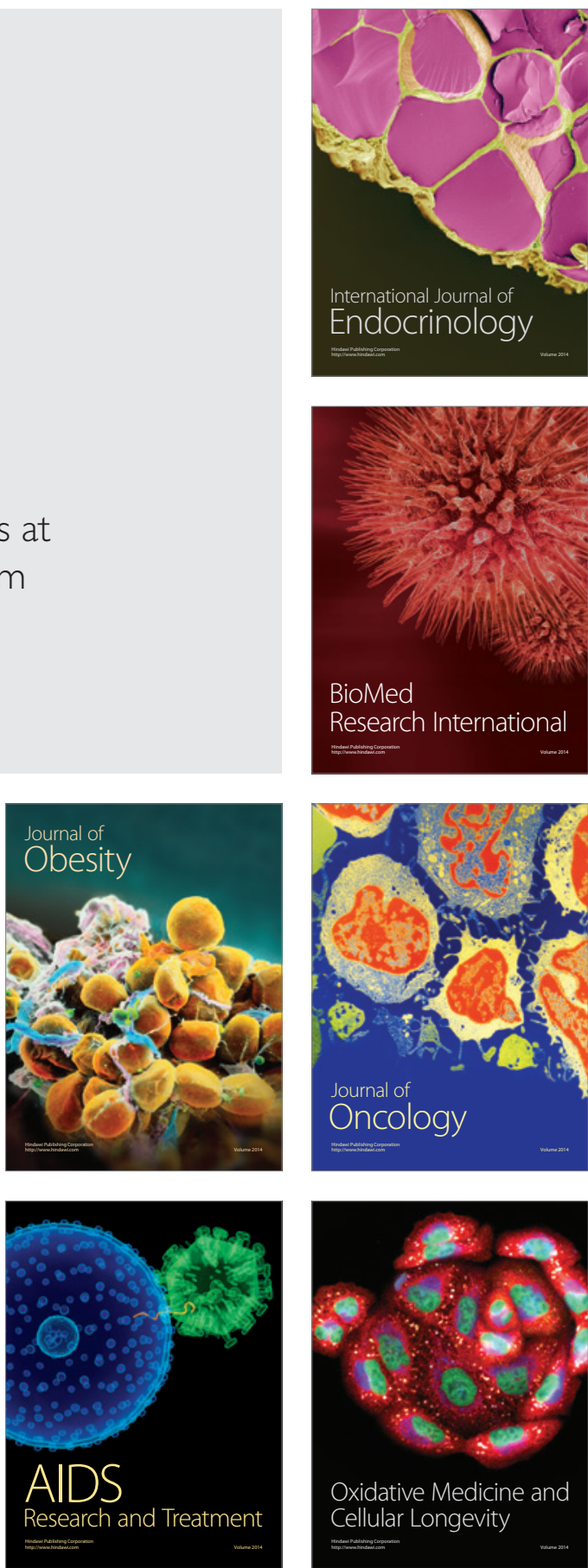